\title{
PERAN E-LEARNING SEBAGAI MEDIA PEMBELAJARAN DI SMKN 3 KUNINGAN
}

\author{
Ayu Pangestu ', Nuur Wachid Abdul Majid 2 \\ ayupangestu@upi.edu, Purwakarta, Indonesia \\ nuurwachid@upi.edu, Purwakarta, Indonesia
}

\begin{abstract}
ABSTRAK
Era digital memberikan dampak pada bidang pendidikan yang dapat mengubah pola pembelajaran tradisional menjadi pola pembelajaran modern. Pemanfaatan teknologi digital dalam pembelajaran dapat diterapkan dalam sebuah konsep yang dikenal dengan istilah elearning. Adapun tujuan penelitian ini adalah untuk mengetahui bagaimana peranan elearning sebagai media pembelajaran daring di SMKN 3 Kuningan yang dapat membantu dalam proses pembelajaran. Penelitian ini menggunakan metode kuantitatif dengan teknik pengumpulan data survei dan dokumentasi. Jumlah responden pada survei yang dilakukan terdapat 36 responden yang merupakan guru mata pelajaran di SMKN 3 Kuningan. Dari hasil pengolahan data dan analisis diperoleh hasil bahwa sebesar $89 \%$ telah menggunakan elearning secara maksimal oleh para guru dan sebesar $78 \%$ guru berpendapat bahwa elearning telah mumpuni sebagai media pembelajaran interaktif, hal ini dikemukakan berdasarkan dari pengalaman penggunaan. Kelebihan seperti memudahkan guru dalam menyampaikan materi, mudah diakses dimana dan kapan saja, serta dapat melakukan diskusi memlalui fitur yang tersedia menjadi latar belakang peranan e-learning sangat membantu dalam proses pembelajaran.
\end{abstract}

Kata kunci : E-learning; Pembelajaran; Peranan

\section{PENDAHULUAN}

Era digital merupakan istilah yang muncul ketika teknologi informasi seperti jaringan internet mulai berkembang bahkan tidak terbendung. Akibatnya terdapat perubahan pada gaya hidup, interaksi, dan pola pikir manusia yang awalnya masih bersifat manual menjadi cara teknologi digital. Hal ini mempengaruhi di berbagai bidang salah satunya pada bidang pendidikan. Pelaksanaan pembelajaran dengan menggunakan teknologi digital merupakan salah satu proses pembelajaran modern.

Pembelajaran saat ini dapat dilakukan berdasarkan 2 (dua), yaitu pembelajaran secara sinkronus dan asinkronus. Pembelajaran sinkronus merupakan pendekatan pembelajaran dengan cara interaksi pendidik dan peserta didik dilakukan secara bersamaan dengan memanfaatkan teknologi seperti video konferensi (Handhika, 2020). Sedangkan pendekatan secara asinkronus merupakan pembelajaran yang dilakukan dengan cara pendidik menyiapkan dan memberikan bahan materi pembelajaran terlebih dahulu kepada peserta didik, dan interaksi pembelajaran dapat dilakukan kapan saja dan tidak terpaku pada jadwal seperti adanya penugasan kepada peserta didik (Handhika, 2020). Dari pendekatan pembelajaran yang ada saat ini dapat dilihat bahwa peran teknologi digital sangat digunakan sebagai media dalam proses pembelajaran. 
Pola pembelajaran secara tradisional atau dikenal dengan pembelajaran konvensional memiliki ciri guru lebih dominan dalam proses pembelajaran. Pembelajaran konvensional merupakan pembelajaran yang bertujuan menambah pengetahuan daripada menambah suatu tindakan (Sukandi, 2003). Dalam penerapannya guru tetap berperan menjadi sumber belajar sehingga sebagian besar siswa hanya mendapatkan materi yang disampaikan oleh guru saja. Pola pembelajaran seperti ini sudah mulai bergeser dan digantikan oleh konsep pembelajaran modern dimana siswa tidak bergantung kepada guru melainkan siswa dituntut untuk lebih kritis dalam berpikir dan kreatif.

Menurut kamus Oxford e-learning merupakan pembelajaran yang dilakukan menggunakan media elektronik, biasanya internet. E-learning merupakan suatu rujukan umum pada proses pembelajaran dengan aturan siswa belajar menggunakan computer dan tersambung dengan internet (Prawiradilaga, 2016). Dapat dikatakan bahwa e-learning adalah platform yang dapat digunakan dalam dunia pendidikan khususnya pada proses pembelajaran. Proses pembelajaran pada e-learning memberikan peran kepada siswa untuk aktif berpartisipasi sehingga siswa dapat berinteraksi dan membangun kerja sama dalam mendapatkan ilmu pengetahuan (Sari, 2015). Dengan siswa yang berperan aktif pada proses pembelajaran maka sumber belajar yang digunakan pun tidak terpaku terhadap guru saja, siswa dapat berekplorasi dengan sumber belajar yang berasal dari internet, buku, modul, dan lainnya.

Pembelajaran berbasis web memerlukan pusat kegiatan untuk peserta didik, seperti interaksi bersama kelompok, administrasi fasilitas sistem, pendalaman materi, ujian, dan material online (Hartanto, 2016). E-learning sebagai media pembelajaran yang dapat menunjang keberlangsungan Kegiatan Belajar Mengajar (KBM) perlu memperhatikan kegiatan dari para pengguna khususnya guru dan siswa. Setidaknya pengguna dapat melakukan kegiatan pembelajaran seperti akses materi, menjawab tugas, ujian, dan diskusi ketika berselancar menggunakan e-learning. Ada banyak software yang digunakan dalam mengatur konten dalam pembuatan sebuah situs web sebagai media pembelajaran, seperti Moodle, eFront, ATutor, Docebo LMS, Open Conference System, ILIAS, dan OLat. Para pengguna dapat dimudahkan dalam pembuatan sebuah situs dengan menggunakan Content Management System (CMS) yang sudah tersedia.

Pada penelitian sebelumnya terdapat beberapa penelitian mengenai penggunaan e-learning sebagai media pembelajaran yang dilakukan oleh Hartanto (2016). Hasil penelitian yang dilakukan menunjukkan bahwa e-learning dapat dikatakan berhasil apabila dibantu oleh interaksi yang dibangun antar pendidik dan peserta didik, peserta didik dengan fasilitas pendidikan, peserta didik dengan peserta didik, dan adanya pola pembelajaran aktif. Selain itu batasan dari ruang dan waktu dapat diatasi dengam adanya teknologi informasi dan telekomunikasi yang mudah dan murah.

SMKN 3 Kuningan merupakan salah satu sekolah kelompok teknologi industri yang berada di Kabupaten Kuningan, Jawa Barat. Sekolah ini didirikan pada tahun 
1965 dan memiliki 8 kompetensi keahlian, yaitu Bisnis Konstruksi dan Properti (BKP), Desain Permodelan dan Informasi Bangunan (DPIB), Teknik Instalasi Tenaga Listrik (TITL), Teknik Otomasi Industri (TOI), Teknik Audio Video (TAV), Teknik Kendaraan Ringan Otomotif (TKRO), Teknik Bisnis Sepeda Motor (TBSM), dan Multimedia. SMKN 3 Kuningan telah menggunakan e-learning sebagai media pembelajaraan saat ini sebagai penunjang pembelajaran saat daring (dalam jaringan). E-learning yang telah dipakai menggunakan Content Management System (CMS) dari Moodle sebagai perangkat lunak dalam pengaturan konten situs web. Penggunaan elearning ini dapat membantu dalam keberlangsungan pembelajaran khususnya bagi guru yang dipermudah dalam memberi materi pembelajaran.

Berdasarkan latar belakang di atas, maka penulis melakukan pendekatan pemecahan masalah mengenai pemanfaatan e-learning di SMKN 3 Kuningan dengan cara survei kepada para guru mata pelajaran mengenai pengalaman dan pendapat selama menggunakan e-learning. Penulis juga melakukan dokumentasi terhadap e-learning mengenai fitur yang digunakan. Adapun tujuan dari penelitian ini yaitu untuk mengetahui e-learning yang digunakan sudah mumpuni sebagai media pembelajaran.

\section{METODE}

Metodologi yang digunakan dalam penelitian ini yaitu menggunakan metode kuantitatif. Metode kuantitatif merupakan merupakan metode penelitian yang dapat dijelaskan secara pasti melalui angka (Muhammad Darwin, 2021). Metode ini banyak digunakan oleh para peneliti khususnya mahasiswa karena data yang didapatkan dapat dideskripsikan dengan jelas sehingga dapat menghasilkan hipotesis. Lokasi yang penulis ambil untuk penelitian ini yaitu SMKN 3 Kuningan yang terletak di Kabupaten Kuningan, Jawa Barat.

Metode pengumpulan data merupakan cara atau tindakan yang dilakukan dalam memperoleh data pada penelitian. Dalam penelitian ini metode yang digunakan yaitu metode dokumentasi dan survei. Metode dokumentasi digunakan untuk mencari data mengenai hal-hal yang berkaitan dengan pengalaman penggunaan e-learning berbasis Moodle. Kemudian metode survei adalah metode yang menggunakan instrument angket dalam mengumpulkan data (Siyoto, dkk., 2015). Metode survei diberikan kepada responden untuk diinterpretasikan apakah produk yang dikembangkan perlu direvisi atau tidak. Responden dari survei ini berjumlah 36 responden yaitu para guru mata pelajaran SMKN 3 Kuningan selaku salah satu pengguna e-learning sekolah berbasis Moodle. Teknik pengambilan data angket yang dilakukan dengan cara mengisi pertanyaan-pertanyaan di Google Form yang telah disediakan.

Teknik analisis yang penulis gunakan dalam melaksanakan analisis ini yaitu dengan Teknik mendeskripsikan data. Pada tahap mendeskripsikan data, penulis mendeskripsikan data analisis isi dan analisis deskripsi. Analisis isi diperoleh dari tanggapan ahli materi dan ahli media. Analisis deskriptif diperoleh dari penelitian angket melalui uji dari ahli materi dan ahli media. 


\section{HASIL DAN PEMBAHASAN}

\section{HASIL}

Berdasarkan penelitian yang dilakukan diketahui bahwa e-learning telah digunakan oleh para guru dalam proses pembelajaran. E-learning dapat membantu dalam penyampaian materi dan mudah digunakan. Selain itu, terdapat fitur diskusi berupa obrolan chat.

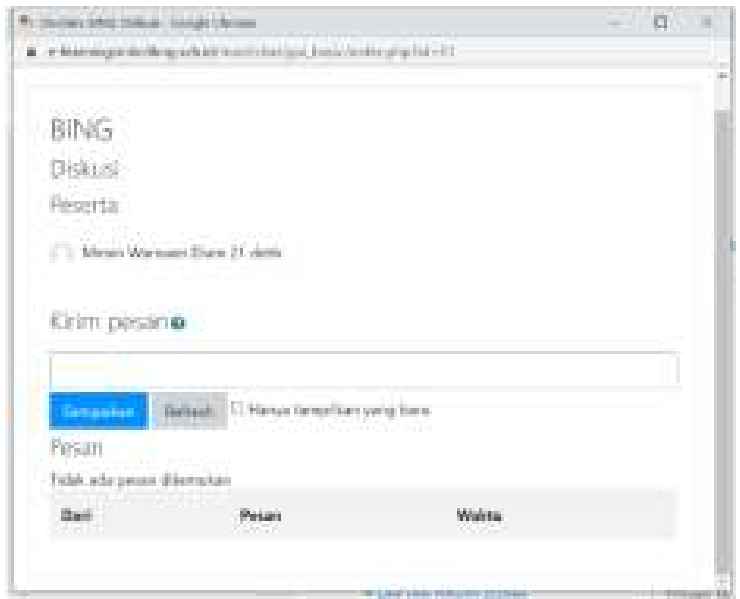

Gambar 1. Halaman Fitur Diskusi E-learning SMKN 3 Kuningan

\subsection{Penggunaan E-Learning Oleh Guru di SMKN 3 Kuningan}

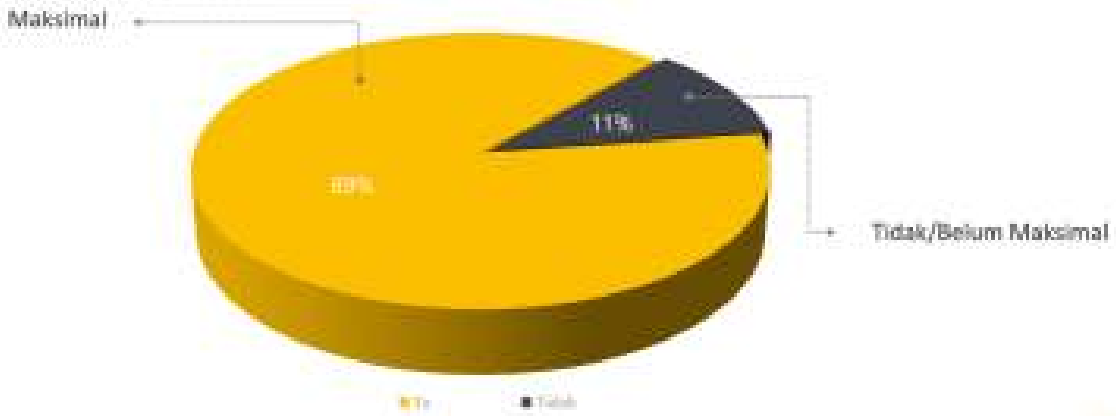

Gambar 2. Diagram Hasil Survei Tentang Penggunaan

Berdasarkan hasil distribusi jawaban dari para responden mengenai penggunaan e-learning dalam proses pembelajaran dapat dibagi menjadi 2 (dua) yaitu maksimal atau tidak maksimal. Dari responden yang menggunakan e-learning diperoleh hasil survei bahwa sebanyak $89 \%$ atau sebanyak 32 guru telah menggunakan e-learning secara maksimal. Kemudian diperoleh $11 \%$ atau sebanyak 4 guru belum menggunakan e-learning secara maksimal. Hal ini berkaitan dengan kelebihan dan kekurangan yang dirasakan oleh para guru selama menggunakan elearning. Adapun kelebihan dan kekurangan e-learning yang diperoleh dari hasil survei adalah sebagai berikut. 
Kelebihan

- Adanya ruang komunikasi dengan siswa berupa diskusi dan pesan

- Dapat memantau kehadiran siswa

- Dapat menyimpan data yang banyak

- Dapat melakukan evaluasi dengan scoring secara otomatis

- Mudah menyusun materi belajar

- Pembelajaran dapat dikontrol oleh pengelola

- Dapat menyampaikan materi untuk beberapa kelas

- Bersifat user friendly

\section{Kekurangan}

- Tampilan yang kurang menarik

- Fasilitas pengumpulan tugas yang belum maksimal

- Belum terdapat platform untuk melakukan konferensi virtual dari e-learning langsung

- Tidak dapat memberikan penjelasan materi secara detail pada siswa

- Siswa aktif dan tidak aktif kurang bisa diketahui

- Waktu absensi tidak spesifik

- Keterbatasan akses internet

- Kurang komunikasi dengan siswa

\subsection{E-Learning Sebagai Media Pembelajaran Interaktif}

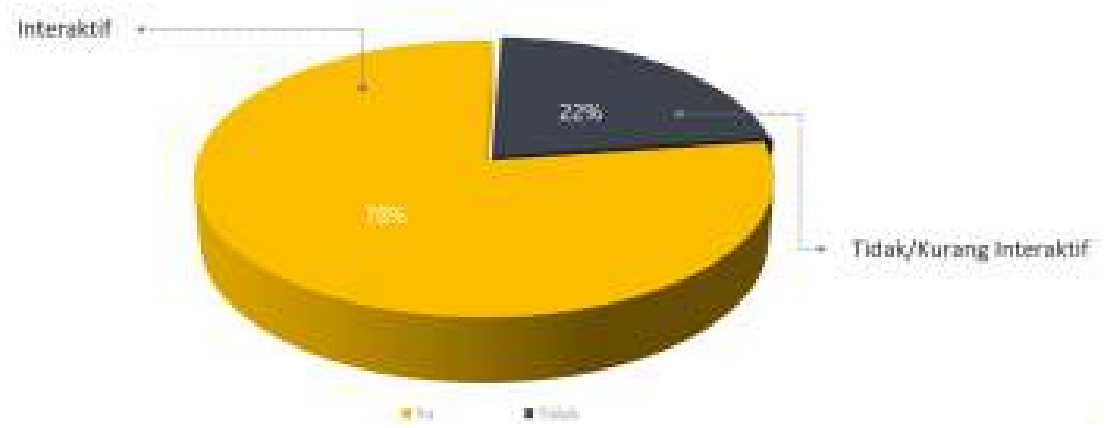

Gambar 3. Diagram Hasil Survei Tentang Media Pembelajaran Interaktif

Berdasarkan hasil distribusi jawaban dari para responden mengenai e-learning dapat ditinjau sebagai media pembelajaran yang interaktif dan kurang interaktif. Dari responden yang menggunakan e-learning diperoleh hasil survei bahwa sebanyak $78 \%$ atau sebanyak 28 guru berpendapat bahwa e-learning yang digunakan sudah mumpuni sebagai media pembelajaran interaktif. Para responen memberi tanggapan bahwa e-learning dapat terkoneksi pada fasilitas untuk 
mendukung Kegiatan Belajar Mengajar (KBM) seperti menggunakan Google Meeting dan Zoom Meeting, guru dapat berkomunikasi dengan siswa melalui diskusi chat, dan dapat menunjang pembelajaran online dengan baik. Kemudian diperoleh $22 \%$ atau sebanyak 8 guru berpendapat bahwa e-learning belum mumpuni sebagai media pembelajaran interaktif. Alasan yang mendasai jawaban ini yaitu pembelajaran yang dilakukan terkesan pembelajaran satu arah dimana guru akan memberikan materi pembelajaran dan siswa hanya mengunduh materi yang diberikan.

\section{PEMBAHASAN}

Berdasarkan hasil pengolahan data terhadap data survei yang diperoleh, dapat diketahui bahwa e-learning di SMKN 3 Kuningan telah dimanfaatkan dalam pembelajaran. Kegiatan pengguna di e-learning yaitu berupa mengakses materi, ujian, absen, dan berita. Dari penyajian gambar 3, dapat diketahui bahwa elearning sudah mumpuni sebagai media pembelajaran interaktif. Penggunaan fitur diskusi pada e-learning dapat membantu pengguna berinteraksi seperti interaksi antara siswa dengan guru, siswa dengan siswa, siswa dengan fasilitas pendidikan, dan terdapat pula konsep pembelajaran modern seperti menggunakan media pembelajaran lainnya yang dapat membantu dalam kelancaran proses belajar.

Akses guru pada e-learning SMKN 3 Kuningan yaitu dapat mengelola kursus pembelajaran sesuai rancangan yang telah dibuat sendiri sesuai struktur yang telah diatur pada e-learning. Walaupun demikian proses penggunaan e-learning yang berperan sebagai jembatan dalam menyampaikan materi pelajaran perlu ditingkatkan agar sesuai dengan e-learning yang baik dan dapat meminimalisir kekurangan yang dirasakan oleh pengguna.

\section{KESIMPULAN}

Berdasarkan hasil pengolahan data dan pembahasan yang dilakukan dan hipotesis yang dikemukakan maka diperoleh kesimpulan sebagai berikut:

a. Penggunaan e-learning sebagai media pembelajaran di SMKN 3 Kuningan telah digunakan dengan baik oleh pengguna khususnya oleh guru sebagai pendidik.

b. Dari fitur yang ada pada e-learning dapat memudahkan pengguna dalam melakukan interaksi yaitu fitur obrolan chatting.

c. Dalam mengembangkan e-learning untuk ke depannya perlu ditingkatkan agar kekurangan yang dirasakan oleh pengguna dapat teratasi.

\section{REFERENSI}

Prawiradilaga, D., dkk. (2016). Mozaik Teknologi Pendidikan E-learning. Jakarta: Prenadamedia Group. 
Handhika, J., dkk. (2020). Pembelajaran Sains di Era Akselerasi Digital. Magetan: CV. Ae Media Grafika

Rachmawati, R., dkk. (2020). Call For Tema 2 (Strategi Pembelajaran). Surabaya: Jakad Media Publishing.

Sukadiono., dkk. (2020). Alam Pikir Era Pandemi "Kajian Lintas IImu". Surabaya: UMSurabaya Publishing.

Sari, P. (2015). Memotivasi Belajar Dengan Menggunakan E-learning. Jurnal Ummul Qura, 6(2), 20-35.

Morissan. (2017). Metode Penelitian Survei. Jakarta: Kencana.

Siyoto, S., \& Sodik, M., A. (2015). Dasar Metodologi Penelitian. Yogyakarta: Literasi Media Publishing.

S, Aidah. (2019). Pemanfaatan E-learning Sebagai Media Pembelajaran di STIA AI Gazali Barru (Suatu Studi Terhadap Pemanfaatan Model E-learning Berbasis Software Claroline). Meraja Journal, 2(1), 1-12.

Yazid, M. (2012). E-learning Sebagai Media Pembelajaran Interaktif Berbasis Teknologi Informasi. Jurnal IImiah Foristek, 2(1), 143-152.

Hartanto, W. (2016). Penggunaan E-learning Sebagai Media Pembelajaran. Jurnal Pendidikan Ekonomi, 10(1).

Aminoto, T., \& Pathoni, H. (2014). Penerapan Media E-Learning Berbasis Schoology Untuk Meningkatkan Aktivitas dan Hasil Belajar Materi Usaha dan Energi Di Kelas XI SMAN 10 Kota Jambi. Jurnal Sainmatika, 8(1), 13-29.

Agustina, M. (2013). Pemanfaatan E-Learning sebagai Media Pembelajaran. Seminar Nasional Aplikasi Teknologi Informasi (SNATI), Yogyakarta, 15 Juni 2013.

Velasquez, R. (2020). How Do You Spell "e" Learning? (and other "e"words). Diakses pada 19 November 2021, dari https://www.infoprolearning.com/blog/how-doyou-spell-e-learning-and-other-e-words/ 